ELORE (ISSN 1456-3010), vol. 18 - 2/2011.

Julkaisija: Suomen Kansantietouden Tutkijain Seura ry.

[http://www.elore.fi/arkisto/2_11/stark.pdf]

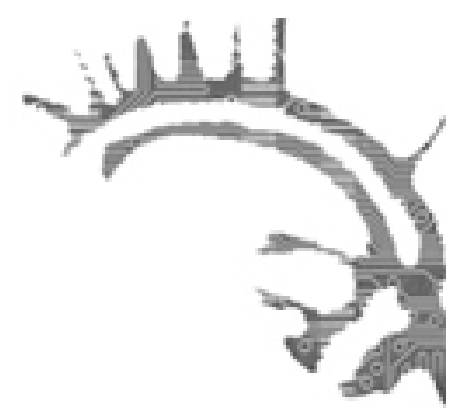

\title{
KANSANKULTTUURIN TUTKIMINEN ON DEMOKRATIAN VAALIMISTA
}

\section{Haastattelussa Satu Apo}

\section{Eija Stark}

Professori Satu Apo on tullut tunnetuksi ennen kaikkea kerronnan tutkimuksesta sekä kansankulttuurin ilmenemismuotoja käsittelevistä tutkimuksistaan. Apolle ominta lähdeaineistoa ovat olleet sadut, Kalevala ja sen runomateriaali sekä monentyyppiset kansanelämän kuvaukset. Tutkijana hän on tiukka empiristi, mikä näkyy aineistoon vahvasti nojaavassa argumentaatiossa, olipa kyse monografiasta tai yksittäisestä artikkelista. Satu Apo siirtyi eläkkeelle alkuvuodesta 2011 ja seuraavassa hän Eloren pyynnöstä muistelee kuluneita vuosikymmeniään tutkimuksen parissa ja yliopistomaailmassa.

\section{KirJallisuUS VAI KANSANRUNOUS?}

Helsingissä syntyneelle ja varttuneelle Satu Apolle humanistinen ala oli jo nuoresta pitäen selviö. Kotitausta oli suorastaan umpihumanistinen; perheessä harrastettiin taiteita ja ennen kaikkea kirjallisuutta laaja-alaisesti.

- Isäni oli äidinkielen lehtori. Hän oli opiskeluaikanaan tehnyt töitä radioteatterille, jota johti Olavi Paavolainen. Perheystäviin kuului taiteilijoita ja filosofian sytyttämiä nuorukaisia. Koska olin intohimoinen lukija, ja ainekirjoitus tuotti koulussa kehuja, suuntautuminen kirjallisuus- ja taideaineisiin tuntui selvältä jo lukiovaiheessa. Vuonna 1967 kuuden ällän ylioppilaat saivat kävellä suoraan sisään humanistiseen tiedekuntaan. Ongelmia minulle tuotti runsauden pula: joka puolella vilkkui toinen toistaan 
Eija Stark: Kansankulttuurin tutkiminen on demokratian vaalimista

houkuttelevampia oppiaineita. Tartuin ensimmäiseksi lukioaikaiseen rakkauteeni, latinaan; yliopistossa se tunnettiin Rooman kirjallisuutena.

Pääaineeksi seuloutui kuitenkin kotimainen kirjallisuus. Suomalainen ja vertaileva kansanrunoustiede oli hyvänä kakkosena. Oppiala ei kuitenkaan heti vakuuttanut.

- Kansanrunouden tutkimus vaikutti epäilyttävältä touhulta. Menin ensimmäisenä opiskelusyksynäni kuuntelemaan akateemikko Martti Haavion esitelmää sammosta. Porthaniaan pakkautunut yleisö sai tietää, että sampo oli kosminen rotaatiokone, joka oli sukua männälle, jolla Intian jumalat kirnusivat maitomerta. Päätin suorittaa kansanrunoudesta vain approbaturin.

Omassa pääaineessa, kotimaisen kirjallisuuden tutkimuksessa elettiin 1960-luvun lopulla kuitenkin suvantovaihetta oppiaineen professorin pitkittyneen sairauden vuoksi. Teoreettisessa ja metodisessa keskustelussa pyöriteltiin 1940-luvun eväitä eli anglosaksista uuskritiikkiä. Uudempia tuulia edustivat Pekka Tarkan praktikumit sekä Ritva Rainion (Haavikon) kirjailijahaastatteluprojekti, johon Apo osallistui tekemällä kaksi haastattelua.

- Kansanrunoudentutkimus sen sijaan kihisi elämää 1960-70-luvulla. Populaarikulttuuri oli nostettu lailliseksi tutkimuskohteeksi; strukturalismia esiteltiin luennoilla laidasta laitaan ja antropologia oli jo noussut esiin ja lujitti jalansijaansa Suomessa Matti Kuusen johtaman oppiaineen suojissa. Väitöskirjoissa käytettiin tilastollisia menetelmiä. Niinpä unohdin kosmisen rotaatiokoneen ja ryhdyin tekemään folkloristiikan proseminaarityötäni Aku Ankan juoniaineksista, venäläisen formalismin ja sarjakuvatutkimuksen innoittamana. Jatkoin vielä laudaturiin vertailemalla unkarilaisen kansankertojan sankarisatua ja Ian Flemingin Bond-seikkailua.

Tutkijanura alkoikin näyttää väistämättömältä jo varhain opintojen aikana.

- Opettajani reagoivat rohkaisevasti jo ennen gradua, joten väitöstyön teko tuntui luontevalta. Julkaisupyyntöjä tuli heti folkloristiikan proseminaarin jälkeen. Opinnäytteiden kautta olin päässyt maistamaan tutkimustyön riemuja ja kauhuja. Olin jäänyt koukkuun, ilmeisesti loppuiäkseni.

Innostus ja laaja-alainen kiinnostus monia oppiaineita kohtaan näkyi nuoren opiskelijan maisterintutkinnon kuuden aineen valikossa. Apolle yliopisto-opettajista moni jäi mieleen virikkeiden antajana.

- Esikuvia olen aina kaihtanut - opetuslapsen tai tietoisen epigonin rooli ei sovi vartalolleni. Matti Kuusi oli kannaltani merkittävin uusien teoreettisten näkymien avaaja. Strukturalistinen narratologia löytyi juuri hänen kursseillaan. Minulla oli ilo istua 1960-luvulla myös erinomaisten naisopettajien luennoilla: Vappu Roos piti yleisen kirjallisuustieteen peruskurssin ja Saara Lilja käsitteli runoilija Martialista. Metodologiseen maailmankuvaani vaikutti yleisen kielitieteen professori Raimo Anttila muistuttamalla, että tieteellinen tieto karttuu kahdella tavalla: löytämällä uutta ja ennen näkemätöntä mutta myös osoittamalla olemassa oleva tieto vääräksi. Kumpikin tapa on yhtä arvokas, painotti Anttila. 


\section{OPiskelijana 1960- JA 1970-LuvUilla}

Satu Apon yliopisto-opintojen suoritusajankohta osui yhteiskunnan murrosvaiheeseen 1960-luvun lopulla ja 1970-luvun alussa. Tuolloin yliopistomaailmassa vanhoja perinteitä ryhdyttiin tietoisesti kyseenalaistamaan ja rikkomaan. Helsingin yliopistossa etenkin valtiotieteellisen tiedekunnan opiskelijat radikalisoituivat. Opiskelijat vaativat yliopiston demokratisoimista. Professorivalta haluttiin murtaa yliopistohallinnossa ensin mies ja ääni -periaatteen mukaisesti, myöhemmin kolmikantaisen hallintomallin avulla. Opiskelijajärjestöt, muiden mukana myös Siula, suomen kielen ja kirjallisuuden opiskelijoiden ainejärjestö, olivat hyvin aktiivisia tässä.

- Kannatin lämpimästi toverien pyrkimyksiä

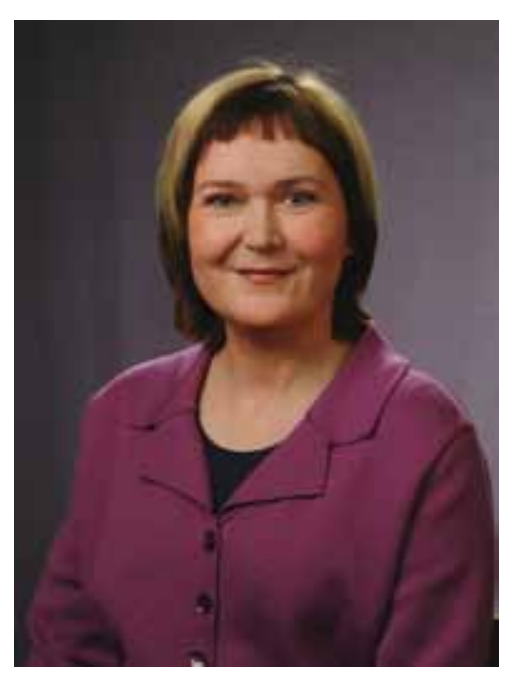

Satu Apo. mutta sivusta käsin, keskittymällä opintoihini. Kohotin kuitenkin tiedostamiseni tasoa kuuntelemalla historiallisen materialismin luentoja Franzeniassa; kurssia veti Veronica Stolte-Heiskanen.

Kaikkien kunnon ihmisten tavoin suoritin sosiologiasta appron. Koska sosiaalipolitiikkakin kiinnosti, tentin saman arvosanan siitäkin. Sosiaalitieteet olivat majakka, jonka avulla suunnistettiin kohti parempaa tulevaisuutta, myös tieteenteossa. Sosiologian metodeja pidettiin esikuvallisina. Erik Allardt ja Antti Eskola olivat humanistienkin kunnioittamia guruja. Klaus Mäkelän luotsaama Alkoholitutkimussäätiö oli tieteellinen Camelot; pienelle humanistille oli suuri kunnia päästä sen kanssa tekemisiin.

Omat radikaalisuuden rajat tulivat Apolla vastaan siinä, mitä voitiin pitää tieteellisenä selittämisenä.

- Vasemmistolaisuuteni rajat tulivat vastaan, kun uudistajat halusivat sisällyttää folkloristiikan tutkintovaatimuksiin Otto-Ville Kuusisen laajan Kalevala-esipuheen, ei tutkimushistoriallisena dokumenttina vaan parempana tutkimuksena kuin mitä meillä oli siihen asti luetettu. Aloittelevana empiristinä ilmoitin, että teksti ei vastannut nykyistä tietoamme Kalevalasta ja kansanrunoudesta.

\section{TutKijanuralle}

Satu Apon kotimaisen kirjallisuuden pro gradu-työ käsitteli Väinö Linnan Pohjantähtitrilogian rakennetta, romaanitekniikkaa ja kertojan roolia. Työ valmistui vuonna 1971, mutta sen keskeiskäsitteet olivat suomalaisittain ajateltuna jo hyvin 80-lukulaisia. Syynä tähän oli kerronnan tutkimuksessa jo 1960-luvun lopulla alkanut paradigman muutos.

- Anglosaksinen kerronnan tutkimus oli edennyt kiinnostavaan vaiheeseen 1960-luvun alkaessa, jo ennen strukturalismin esiinmarssia. Kohteena oli kerrontatekniikka eli sen selvittäminen, miten kirjailija oli rakentanut romaanitekstinsä, ja millä keinoin 
Eija Stark: Kansankulttuurin tutkiminen on demokratian vaalimista

hän välitti lukijalle omaa tulkintaansa kertomuksestaan. Otin tukea Wayne C. Boothin maineikkaasta opuksesta The Rhetoric of Fiction ja kävin Pohjantähden kimppuun. Romaani sopi aloittelevan narratologin kohteeksi, koska sen kerrontatekniikka oli hyvin perinteinen.

- Sosiolingvistit - tarkoitan erityisesti William Labovia ja Joshua Waletzkya käsittelivät samoja kysymyksiä 60-luvun lopulla tutkiessaan suullista kokemuskerrontaa. Heidän analyysimallinsa rantautui suomalaiseen folkloristiikkaan 1980-luvulla.

Nuorta tutkijaa teoria puhutteli vahvasti. Saduntutkimuksen Apo löysi sitä kautta, että kiinnostui Vladimir Proppin ja kumppaneiden teoriasta.

- Kriittisenä henkenä aloin epäillä Proppin kuuluisan juonikaavan yleistettävyyttä ja vähitellen koko kaavan logiikkaa. Halusin testata asiaa konkreettisten kansansatutallenteiden avulla. Tähän tarjoutui ensimmäinen tilaisuus, kun selvittelin Marina Takalon satujen, legendojen ja uskomustarinoiden rakenteita Juha Pentikäisen tutkimusapulaisena 1970-luvun alussa.

Työ satujen parissa johti Eero Tarastin vetämään strukturalismiryhmään, joka oli kiinnostunut etenkin Claude Lévi-Straussin ajattelusta. Kirjallisuustieteissä strukturalistien kovin kortti oli Roland Barthes. Ryhmä julkaisi vuonna 1974 teoksen Strukturalismia, semiotiikkaa, poetiikekaa. Apon mukaan tuolloin sovelletun strukturalismin anti heijastui omaan tapaan tehdä tutkimusta myöhemminkin.

- Osa strukturalisteista oli kiinnostunut suhteuttamaan kertomusten rakenteita kulttuurin sosiaalisiin ja taloudellisiin rakenteisiin. Homologian tai isomorfian löytyminen koettiin merkittäväksi. Itselläni kontekstuaalinen analyysi sai tätä kautta uutta potkua. Muistelin näitä virityksiä tehdessäni väitöstyötäni kansansaduista mutta myös aloitellessani viinatutkimustani 80-luvun lopulla.

Lopullinen valinta folkloristiikan ja kirjallisuuden tutkimuksen välillä oli lopulta helppo, sillä alkujaan Volter Kilvestä suunniteltu väitöskirja-aihe sai väistyä saduntutkimuksen tieltä. Turun yliopiston folkloristiikan assistenttina Satu Apo aloitti 1976, jonka ohessa väitöstutkimus alkoi muotoutua.

Toisin kuin proppilaisen teorian johtaminen satujen tutkimiseen, kognitiiviset käsitteet löytyivät halusta kuvata jäsentyneellä tavalla vanhan kansan alkoholiin liittyvää ajattelua.

- Teoria ja käsitteistö, jolla opiskeluaikoinani kuvattiin perinteen kollektiivista ulottuvuutta - kollektiivitraditio, traditiodominantti, stereotypia, teema tai uskomus vastasivat mielestäni huonosti niihin kysymyksiin, joista olin kiinnostunut. Sen sijaan kognitiopsykologia ja lingvistiikka tarjosivat malleja ihmisten käyttämistä tietorakenteista. Antropologit ja muut kulttuurin tutkijat - Turussa etenkin Matti Kamppinen - alkoivat pakata näihin muotteihin myös tietoa, jota he olivat tuottaneet analysoimalla erityyppisiä lähdetekstejä, muitakin kuin kertomuksia. Seurasin kognitiivisten käsitteiden käytössä siis esimerkkiä. 
Eija Stark: Kansankulttuurin tutkiminen on demokratian vaalimista

\section{TUTKIJAN MONIULOTTEISUUS}

Yksi Satu Apon tutkimusintresseistä on ollut vanha suomalainen maalaisyhteisö ja sen sosiaalisten suhteiden hierarkiat. Etenkin agraarista sukupuolijärjestelmää tavalla tai toisella käsittelevissä artikkeleissa tai tutkimuksissa Apon Naisen väki -teosta on siteerattu paljon yli oppiainerajojen. Naisen asemaan liittyvät historialliset prosessit Apoa alkoivat kiinnostaa jo väitöskirja teon aikana 1980-luvulla: kansansaduissa naisen osa ja paikka ovat vahvasti esillä.

- Koska maalaisnaisia ja -perhettä koskevaa tutkimusta oli tuolloin kovin niukasti saatavilla, menin historiaan kaunokirjallisuuden kautta. Selvittelin Seitsemän veljeksen antamaa kuvaa sukupuolten suhteista työskennellessäni 1980-luvulla pohjoismaisessa Folklore och litteratur -projektissa, jota veti Nordiska Museet'n kansanperinnekokoelmista vastaava johtaja Ebbe Schön. Myös pohjoismaisen naiskirjallisuuden historia -hanke vei minut sukupuolikysymysten äärelle. Suomen osuus tehtiin Maria-Liisa Nevalan johdolla. Kirjoitin yleisesityksen naisia käsittelevästä ja naislaulajien osaamasta kalevalamittaisesta runoudesta projektin julkaisemaan "Sain roolin johon en mahdu". Suomalaisen naiskirjallisuuden linjoja.Suomalaisen naiskirjallisunden linjoja. Naislinjalla pysyttelin myös toimiessani Aili Nenolan johtaman Kulttuuri, perinne ja sukupuoli -projektin johtoryhmässä.

Myöhemmin kiinnostus laajeni tyttöihin ja heidän asemaansa maalaisperheissä. Tähän tarjosi näkymän Satasärmäinen nainen -elämäkertakilpailun (1991) sato. Apo ryhtyi tarkastelemaan tyttöihin ja nuoriin naimattomiin naisiin liittyviä kulttuurisia malleja historiallisesta näkökulmasta käsin. Myös eurooppalaisia satuklassikoita, ns. prinsessasatuja, joita kehitteli omien naiskäsityksiensä mukaan meillä Suomessa Zacharias Topelius, Apo on analysoinut historiallisesta perspektiivistä käsin. Apon genustutkimuksista puhuttaessa ei voi olla mainitsematta suurta huomiota saanutta väki-käsitettä.

- Naistutkimuksessa ja muussakin kulttuurintutkimuksessa oltiin 1980-luvulla hyvin kiinnostuneita seksuaalisuudesta ja ruumiillisuudesta. Kaikki folkloristit tiesivät, että kansanperinne on tällä alueella erityisen rikasta. Teema oli itse asiassa korkattu jo edellisellä vuosikymmenellä, jolloin kaadettiin julkaisutabuja esimerkiksi Isojen poikien laulukirjalla (toim. Otso I. Hipiäinen). Nyt oli naisten vuoro. Esimerkkejä väki-käsitteen merkityksistä ja käytöistä löytyi magian tutkimuksen traditiosta. Toivo Vuorelan klassikko Paha silmä suomalaisen kansanperinteen valossa oli hyvä ensiapupakkaus. "Naisen väki" vilahti myös Matti Sarmelan tekstissä. Kansainvälisessä sukupuolentutkimuksessa nousi esiin yhä rohkeampia teorioita, esimerkkinä Hélenè Cixous'n tai Thomas Laqueurin näkemykset. Niinpä tulkitsin naisen väkeä myös oman pääni mukaan.

Väki-käsite oli kansanomaisen ajattelun yksi representaatio. Viinan voima -tutkimuksessa (2001) olikin mahdollista yhdistää monia siihenastisia kiinnostuksen kohteita: kansanomaista alkoholin käyttöä ja siihen liittyviä käsityksiä, suomalaista agraarikulttuuria sekä erilaisia folkloreaineistoja. Ominaista Viinan voimalle on aineistojen tiukka sitominen yhteiskuntahistoriaan.

- Heräsin historiallisten kontekstien olemassaoloon jo väitöskirjaa tehdessäni. Työskentelin tuolloin Turun folkloristiikan oppiaineessa, jossa painotettiin vahvasti 
Eija Stark: Kansankulttuurin tutkiminen on demokratian vaalimista

kenttätyötä. Niinpä kontekstista puhuttiin jatkuvasti. Lauri Honko jaksoi vuodesta toiseen painottaa, että hyvää folkloristista tutkimusta oli (miltei) mahdotonta tehdä ilman tutkijan ja informantin yhteistyötä; tämän oli oltava myös pitkäkestoista.

- Kuten tunnettua, kansansadut ovat SKS:n kansanrunousarkistossa tallenteina, jotka vaikenevat kertojastaan, ainakin antropologisessa mielessä. Honko opetti, että tällaiset tekstit ovat tyhjiä merkityksistä. Kieltäydyin uskomasta tätä. Jos kertojaan kytkeytyviä konteksteja ei voida tavoittaa, tutkija voi aina sijoittaa arkistotekstit muihin yhteyksiin ja saada tällä tavoin aineistonsa keskustelemaan historiantutkimuksen tuottaman tiedon kanssa. Siihen, mitä konteksteja ryhdyin rakentelemaan, vaikuttivat muistumat tietyistä strukturalismin suuntauksista, jotka vertailivat kertomuksen rakenteita yhteiskunnallisiin tai yhteisöllisiin rakenteisiin. Tällaisia strukturalisteja olivat esimerkiksi Lucien Goldmann ja Claude Lévi-Strauss.

Käytin samaa asetelmaa Viinan voimassa. Työskennellessäni Turussa Alkoholitutkimussäätiön sopimustutkijana otin lusikan kauniiseen käteen ja ryhdyin syventämään Suomen historian tuntemustani istumalla muun muassa Pentti Virrankosken taloushistorian luennoilla. Lukuelämyksistä merkittävimmät syntyivät uuden ruotsalaisen perhehistorian äärellä.

\section{KOLMAS ELÄMÄ}

Satu Apo siirtyi eläkkeelle 1.3.2011. Eläkepäivillä olossa mukavinta on ollut se, että on saanut tehdä asioita oman aikataulun mukaan. Työn alla on parhaillaan yksi väitöskirjan esitarkastus, mutta pääasiassa saa keskittyä siihen, mistä eniten pitää eli tutkimiseen. Tällä hetkellä hän tutkii Aleksis Kiven tuotantoa, osana Suomalaisen Kirjallisuuden Seuran organisoimaa klassikkokirjailijoiden kriittisten editioiden toimittamista, joka on aloitettu Aleksis Kivestä Jyrki Nummen johdolla.

- Olen mukana Kiven Kullervon toimitustyössä. Olen laatinut selvityksen Kiven draaman suhteesta Lönnrotin Kullervoon. Tätä tehdessä avautuikin uusia näkymiä Kalevalan ja suomalaisen mytologian vastaanottoon, joka oli herkullisen ristiriitaista.

Tutkimukseen keskittymisen lisäksi toinen mukava kokemus eläkeläisyydestä on ollut se, että kuntoilu maistuu makealta. Jatkossa professori emerita aikoo katsella, mitä muuta kivaa kolmannella elämälle on tarjota, jos terveys kestää. Folkloristiikan tulevaisuuden näkymät kuitenkin huolettavat, ja toiveena on aikojen ja tiedepoliittisten trendien muuttuminen nykyisestä.

- Humanistisia ohjelmia karsitaan vetoamalla taloudellisiin syihin ja hyötynäkökohtiin. Sivistys näkyy menettäneen itseisarvonsa. Suomalaisilla on kuitenkin oikeus saada tutkittua tietoa omasta kulttuuristaan. Folkloristien työt herättävät jatkuvasti kiinnostusta sekä mediassa että lukijoiden keskuudessa. Kansankulttuuriin kohdistuvan tutkimuksen ja opetuksen ajaminen alas on myös demokratian polkemista.

Nuorelle tutkijapolvelle kokeneemmalla tekijällä on kysyttäessä esittää muutama vinkki. Ensiksikin kaikkina aikoina kannattaa etsiä painokkaita ja mielenkiintoisia tutkimusaiheita. Lisäksi kannattaa käyttää meheviä aineistoja, soveltaa ajantasaista teoriaa ja mieluimmin kehittää sitä itse. 
Eija Stark: Kansankulttuurin tutkiminen on demokratian vaalimista

- Teoria on empiirisessä tutkimuksessa hyvä renki mutta huono isäntä; sen ylivalta verottaa työn kiinnostavuutta, usein myös luettavuutta. Metodipuolella kannattaa valita, kehitellä tai keksiä menetelmiä, jotka ovat selkeitä ja tuottavat mielenkiintoisia tuloksia. Argumentoinnin vakuuttavuutta voi vahvistaa oman työn säälimättömällä reflektiolla. Aiheen painokkuutta ja kiinnostavuutta voi arvioida etukäteen lähiaineiden tutkijoiden ja ulkomaisten kollegojen avulla - jos he ymmärtävät, mistä on kyse ja vaikuttavat uteliailta, olet vahvoilla.

FT Eija Stark on tutkija Helsingin yliopiston folkloristiikan oppiaineessa. 